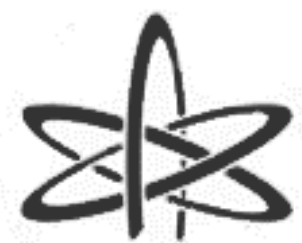

BJRS
BRAZILIAN JOURNAL

$\mathrm{OF}$

RADIATION SCIENCES

08-03A (2020) 01-19

\title{
Periodic Inspection Program of Nuclear PWR reactor Pressure Vessels
}

\author{
Aguiar de Araujo ${ }^{\mathrm{a}}$.Anne \\ ${ }^{a}$ Amazônia Azul Tecnlogias de Defesa S.A. - Amazul - São Paulo, Brazil \\ anneaguiar@hotmail.com
}

\begin{abstract}
This work aims to present a methodology that guides the operating organization to carry out periodic inspections in the nuclear PWR reactor pressure vessels. First, fundamental concepts of nuclear energy and their applications are discussed. This discussion allowed the presentation of functions and characteristics of PWR reactor pressure vessels and the understanding of damage and effects of irradiation in the materials used in the manufacture of these vessels. From the recommendations of codes and publications related to pressure vessel integrity and inspections, for nuclear applications, the minimum requirements that should be considered in the inspection program preparation for this equipment were established. Furthermore, this paper shows the advantages of using computational tools to manage inspection results, allowing the operators to plan and monitor maintenance activities so as to avoid financial loss and environmental damage.
\end{abstract}




\section{INTRODUCTION}

The PWR reactor pressure vessel performs as the key component of the primary circuit pressure barrier, therefore it serves a safety function. Hence, it is fundamental to manage its integrity because not only is it a mechanical equipment, but also an important item for reactor safety.

Thus, for the assessment and management of equipment integrity it is necessary to: identify possible damage; collect and integrate design, operation and inspections data; evaluate the severity of the risk scale and prioritize actions to be taken. The inspections are tools used to support integrity management since from them it is possible to identify the severity of anomalies, monitor the damage evolution and from these results to plan and execute mitigation actions.

This paper presents a methodology which guides the operating organization to conduct periodic inspections in the nuclear PWR reactor pressure vessels. Initially, a bibliographic review was presented to introduce information related to PWR nuclear reactors, as well as a study on the damage and irradiation effects in the materials used in the manufacture of PWR reactor pressure vessels. Finally, the minimum steps and requirements that should be taken into account during the preparation for the inspection program for the equipment were established from the recommendations of codes and publications related to pressure vessel integrity and inspections, regarding nuclear applications.

The nuclear power plants aim to generate electricity, in other words, they convert nuclear energy into electricity. This is done through nuclear reactors in which occurs fission of uranium and plutonium atoms through neutrons with specific energies. The database on nuclear power reactors by Power Reactor Information System - PRIS indicates that, currently, there are, in the world, 442 power reactors in operation and 53 under construction.

Figure 1 relates the number of reactors in operation to their types. Moreover, it shows that most of the world's reactors are PWR (Pressurized Water Reactor). PWR corresponds to the second generation of reactors whose main characteristics are the use of enriched uranium and light water as a coolant and a neutron moderator. 
Figure 1: Number of Reactors in Operation x Type

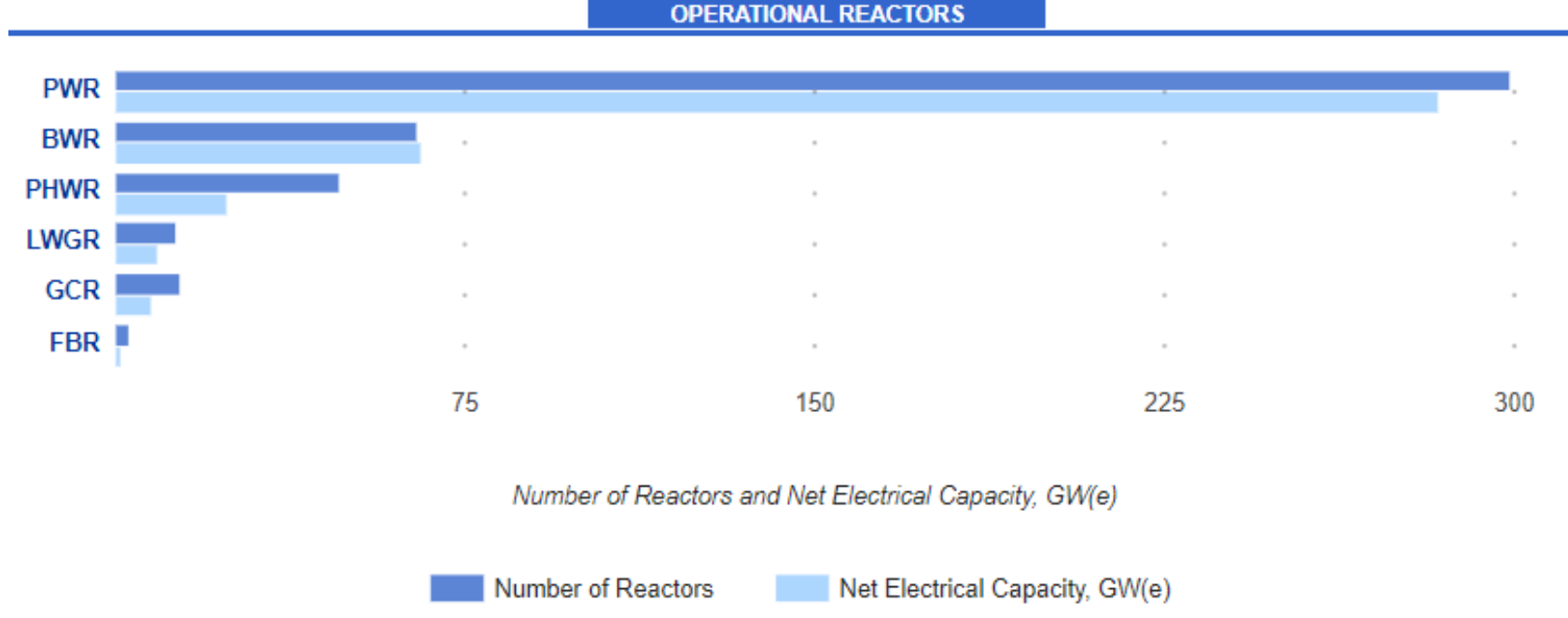

Source: Power Reactor Information System - PRIS website [1]

\section{Label}

BWR - Boiling Light-Water Cooled and Moderated Reactor FBR - Fast Breeder Reactor

GCR - Gas Cooled, Graphite Moderated Reactor

LWGR - Light-Water Cooled, Graphite Moderated Reactor

PHWR -Pressurized Heavy-Water Moderated and Cooled

Reactor

PWR - Pressurized Light-Water Moderated and Cooled Reactor

Currently, there are 2 PWR reactors operating in Brazil in order to generate electricity. Table 1 shows their main characteristics.

Table 1 - Characteristics of Brazilian Power Reactors in Operation

\begin{tabular}{cccc}
\hline Name & Location & $\begin{array}{c}\text { Electrical Capacity } \\
{[\mathbf{M W}]}\end{array}$ & Type Reactor \\
\hline Angra I & Angra dos Reis - RJ & 640 & $\begin{array}{c}\text { PWR } \\
\text { (Westinghouse) } \\
\text { Angra II }\end{array}$ \\
Angra dos Reis - RJ & 1350 & $\begin{array}{c}\text { PWR } \\
\text { (Siemens) }\end{array}$ \\
\hline
\end{tabular}


PWR reactors have two major systems classified as: primary and secondary. In the PWR primary cycle there is fission of uranium atoms, causing the heating of the water flowing through the reactor. As the definition of this type of reactor indicates, the water is pressurized in order to prevent it from boiling.

The steam generator performs the heat exchange of the water of the primary system and thus, the required steam is supplied to the secondary cycle in order to turn the turbine which drives the electric generator to generate electrical power. The condenser in the secondary system aims to recover the steam coming from the turbine. Instead of releasing the steam into the atmosphere, it removes the excess heat causing the steam to condense. This condensation allows water to be pumped back into the steam generator for reuse. This process is clearly illustrated in figure 2 .

Figure 2: PWR Power Plant Diagram

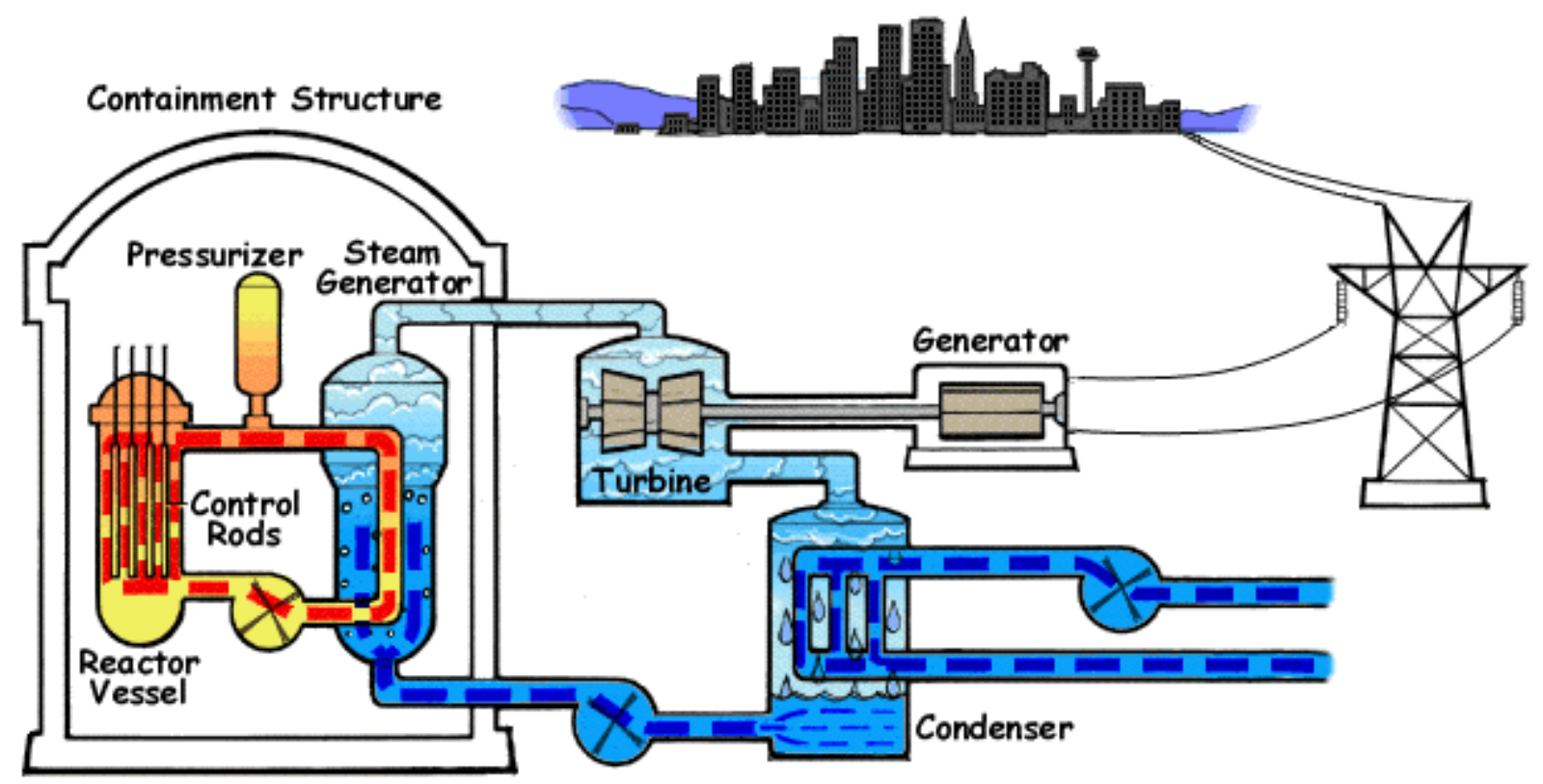

Source: NRC website [2]

The PWR reactor components are classified as nuclear fuel, structures, moderators, absorbers, coolants and shielding [3]. In this paper, the focus is given to the reactor pressure vessel, the most important structural component of a PWR nuclear power plant. 


\section{REACTOR PRESSURE VESSEL}

Since failure in pressure vessels can result in catastrophic consequences, their design and construction involve certain precautions and require knowledge of codes and selection of suitable materials for each type of application. For the design and manufacture of pressure vessels used in PWR reactors, generally, the criteria recommended by the ASME Boiler and Pressure Vessel (BPVC), Section III, Division I are applied.

In general, the body of the vessel is fabricated with low-alloy carbon steel and its inside surface is clad with austenitic stainless steel to minimize the corrosive effects, as shown in table 2 . In Brazil, the Angra I reactor was designed by an American company with the following specifications: SA 533 Grade A Class 2, SA 508 Class 2 (body of the vessel) and AISI 304 (cladding). The Angra II reactor, on the other hand, was supplied by a Germany company with specifications as follows: $20 \mathrm{Mn}$ Mo Ni 55 (body of the vessel) and AISI 316 L (cladding).

Table 2 - Typical Materials for Reactor Pressure Vessel (RPV)

\begin{tabular}{ccc}
\hline Country & Shells & Austenitic Cladding \\
\hline USA & SA302 GR B & TYPE 308L, 309L \\
& SA533 GR B Class 1 & TYPE 304 \\
& SA 508 Class 2 & \\
& SA 508 Class 3 & \\
France & 16 MnD5 & \\
Germany & 20MnMoNi55 & \\
& 22NiMoCr3 7 & \\
\hline
\end{tabular}

The main failure modes of a pressure vessel are: excessive elastic deformation including instability; excessive plastic deformation; brittle fracture; creep failure; plastic instability and accumulation of plastic deformations; low-cycle fatigue; stress corrosion cracking and fatigue corrosion. The risk of such failures may be minimized with the selection of the suitable material, although there is always degradation of the material; therefore, the inspection appears as a collaborative tool in the monitoring of these failure modes. 


\subsection{Damage and Radiation Effects in the Reactor Pressure Vessel}

Every material has imperfections or defects in its lattice. Crystalline defects are irregularities with one or more dimensions in the order of atomic diameter and they are important because they influence the properties of the material, such as the mechanical properties. The imperfections present classifications according to their geometry or dimension, as shown below:

- Point Defects (associated with one or two atomic positions) - e.g. vacancy and interstitial atom;

- Linear Defects (one-dimensional) - e.g. dislocation;

- Interfacial Defects (two-dimensional) - e.g. grain boundaries, stacking faults;

- Volume Defects (three-dimensional) - e.g. voids, bubbles.

Under radiation, the crystalline defects produced are dependent on: neutron flux, energy spectrum, time and irradiation temperature, crystal structure, impurity atom and alloy elements of the material.

In PWR reactors, radiation damage is produced when neutrons have enough energy to create the displaced atom by primary knock (PKA) that moves resulting in displacement cascades which generate a large number of defects, for example: vacancies and interstitial atoms. The effects of these kinds of damage are a noticeable microstructural alteration that generally occurs in materials' properties, for instance, the mechanical properties. Thereby, the change in the mechanical properties of irradiated materials is determined by microstructural alteration resulting from the formation, migration and cluster of defects, the existence of transmuted atoms and, in some specific cases, the physical-chemical interaction of the material with the environment in which it is inserted.

The major degradation mechanism of a pressure vessel is the embrittlement of material caused by fast neutron irradiation in the vessel wall, adjacent to the core. The embrittlement brought by irradiation and low temperatures act to reduce the fracture toughness of RPV material. It is important to emphasize that this irradiation embrittlement is strongly influenced by the presence of copper, nickel and phosphorus, hence the concentration of these elements as impurity in materials employed in the manufacture of RPV has decreased over the years. Moreover, $\mathrm{Cu}, \mathrm{Ni}$ and $\mathrm{P}$ contents were also limited in welding processes. 
Some examples of the irradiation effects on mechanical properties are presented in table 3.

Table 3 - Effects of Irradiation on Mechanical Properties in PWR Reactor Pressure Vessel

\section{Mechanical Properties}

\begin{tabular}{ccc}
\hline Description & Increase & Decrease \\
& $\mathrm{X}$ & $\mathrm{X}$ \\
Yield stress & $\mathrm{X}$ & \\
Ultimate Stress & $\mathrm{X}$ & \\
Ductility & $\mathrm{X}$ & $\mathrm{X}$ \\
Hardness & $\mathrm{X}$ & \\
Embrittlement & & \\
Ductile-to-brittle Transition & & \\
Low-Cycle Fatigue Strength &
\end{tabular}

Additionally, as an effect of neutron irradiation, the Irradiated Assisted Stress Corrosion Cracking (IASCC) can also be mentioned as an aging mechanism which introduces damage in components of nuclear power plants, changing their characteristics over time. This aging degradation mechanism can be observed in reactor internal components and there are three necessary conditions for this to occur: susceptibility of a material, existence of tensile stress and a corrosive environment. Thus, the elimination or reduction of any one of these elements may, in principle, prevent stress corrosion cracking.

\subsection{Examples of Effect Irradiation on Mechanical Properties}

The PWR reactor pressure vessels are fabricated with materials that exhibit the ductile-to-brittle transition behavior. Based on the temperature dependence of measured impact energy, it is possible to determine whether a material experiences a ductile-to-brittle transition and, if it does, the temperature range over which such a transition occurs, as seen from figure 3 . Charpy and Izod impact tests are used to measure the ductile-brittle transition temperature, defined as the temperature below which the material fracture is brittle. 
Figure 3: Impact Test Result [5]

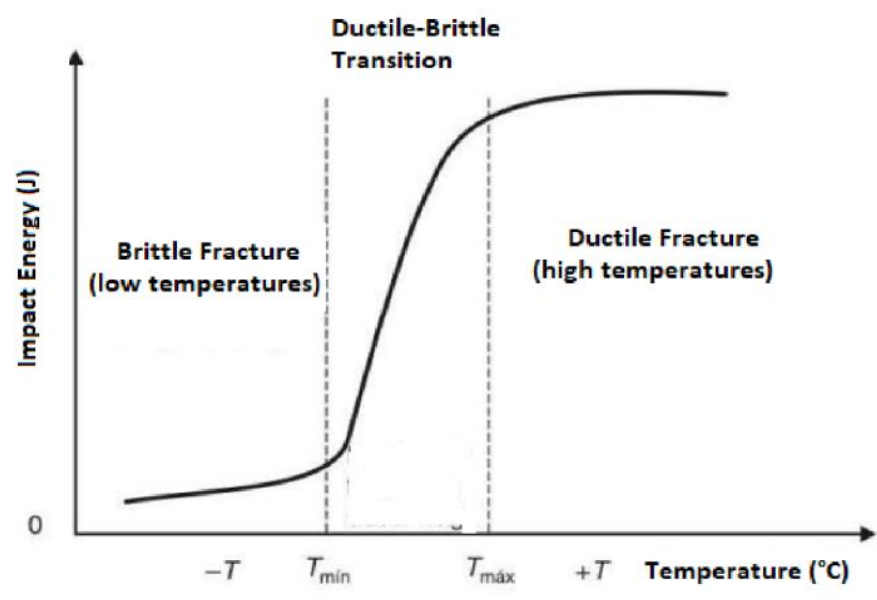

Source: Ensaios dos Materiais, Garcia, A., LTC - Rio de Janeiro, 2ª ed, 2012 [5]

From figure 4 it is possible to observe the change in the curve of impact test for irradiated material. The figure also shows that there is an increase in ductile-brittle temperature and a decrease of absorbed energy, which means that the material can fail by brittle fracture at high temperatures.

Figure 4: Influence of Irradiation on the Charpy Curves

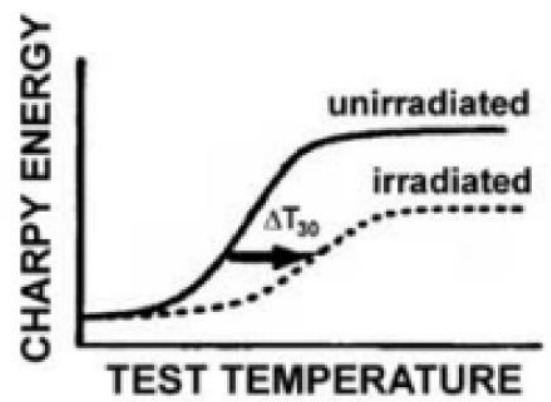

Source: Integrity of Reactor Pressure Vessels in Nuclear Power Plants: Assessment of Irradiation Embrittlement Effects in Reactor Pressure Vessel Steels- IAEA. [4] 
The stress-strain curves for unirradiated and irradiated material are presented in figures 5 and 6 , allowing the comparison of the following mechanical properties in both cases: yield strength, ultimate strength and strain.

Figure 5 - Effect of irradiation on the stress-strain curve - Material: Ferritic Steel

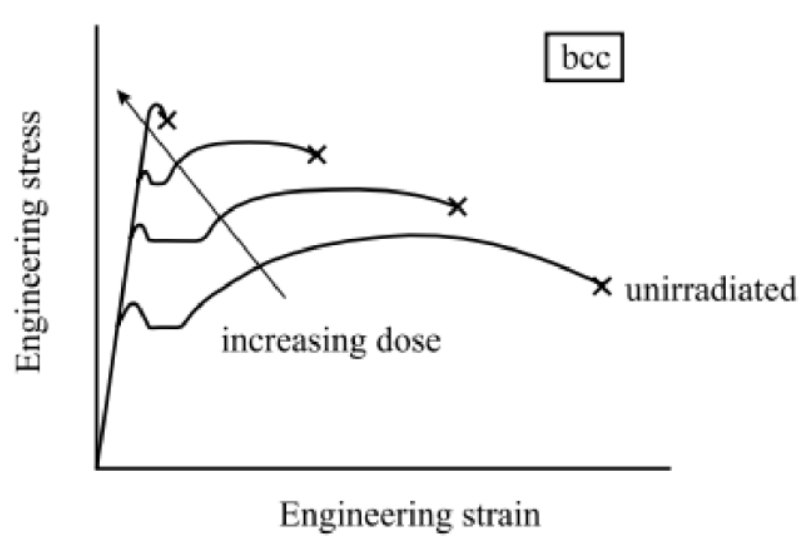

Figure 6 - Effect of irradiation on the stress-strain curve - Material: Austenitic Stainless Steel

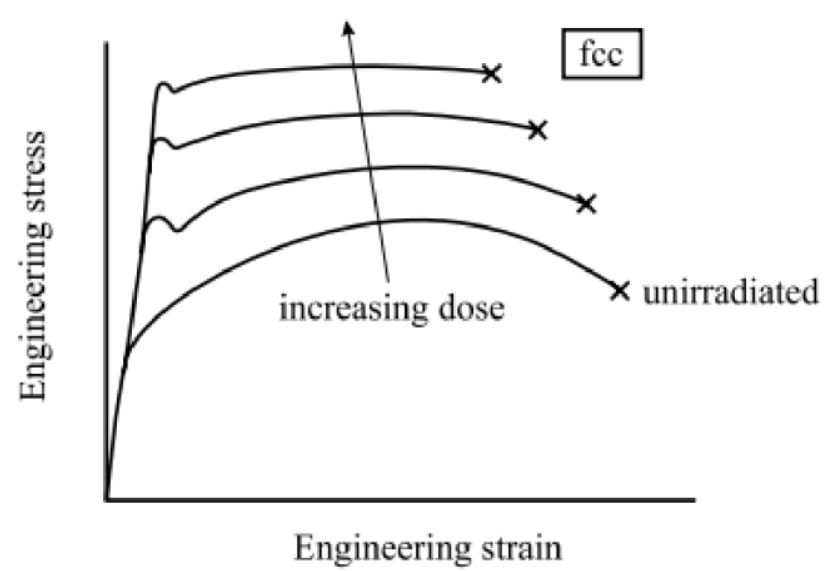

Source: Fundamentals of Radiation Materials Science: Metals and Alloys, Was, G.S, Springer, 2007. [6]

The previous figures show that irradiated material presents an increase in the yield strength and the ultimate strength, but, on the other hand, a decrease in the strain material. In addition, the comparison between the behavior of the stress-strain curve for the austenitic stainless steel and the ferritic steel indicates a considerable reduction in the plastic deformation with the increase of the irradiation for ferritic steel, since it was observed that for this material the rupture occurs still in the elastic area of the curve.

Concerning hardness, which is a mechanical property defined as the measure of a material's resistance to plastic deformation, figures 5 and 6 express the increasing material hardness in consequence of the reduction of plastic deformation for irradiated materials. 
Another mechanical property whose irradiation effects should be considered is the fracture toughness, a measure of a material's resistance to brittle fracture when a crack is present. Due to the irradiation, the decreasing fracture toughness and the transition temperature shift are observed, as shown in figure 7.

Figure 7: Effect of irradiation on fracture toughness

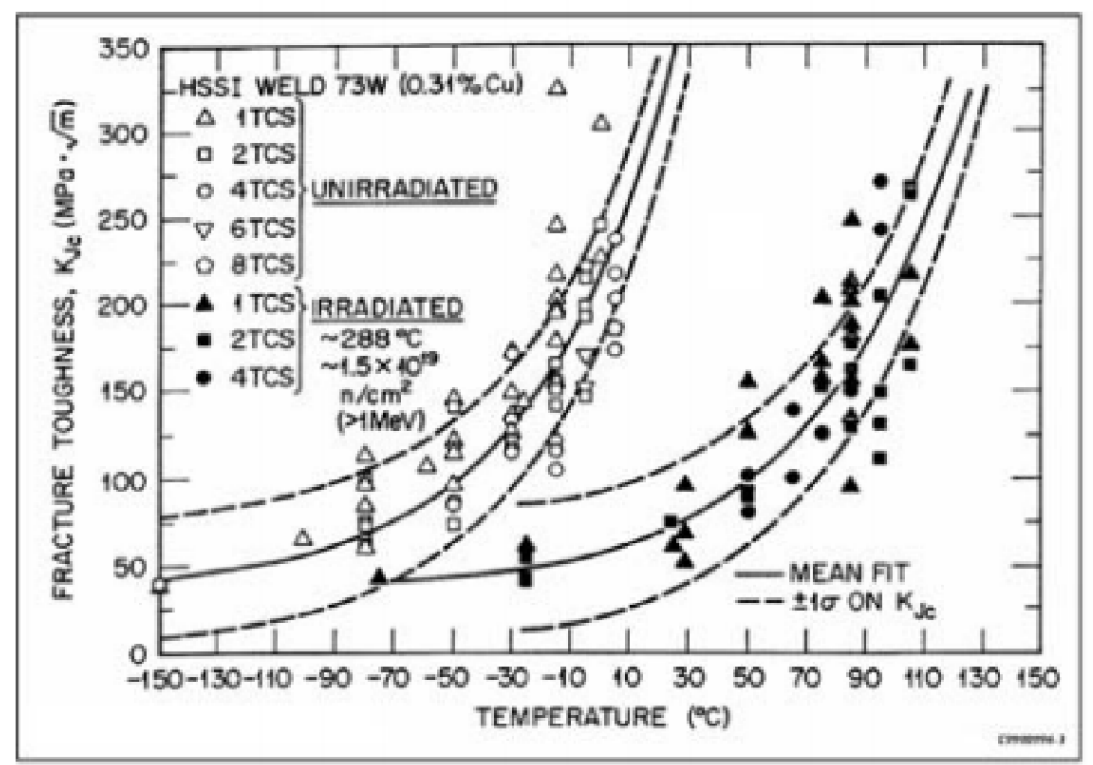

Source: Integrity of Reactor Pressure Vessels in Nuclear Power Plants: Assessment of Irradiation Embrittlement Effects in Reactor Pressure Vessel Steels- IAEA. [4]

\section{PERIODIC INSPECTION IN PWR REACTOR PRESSURE VESSEL}

For monitoring the effects of irradiation previously presented, a periodic inspection program is necessary as a tool to evaluate the pressure vessel integrity. This work is based mainly on recommendations of the Brazilian National Commission for Nuclear Energy (Comissão Nacional de Energia Nuclear - CNEN), which is the regulatory body.

The code CNEN NE 1.25 - In-Service Inspection in Nuclear Power Plants - establishes the minimum requirements applicable to in-service inspections in nuclear power plants. For this code, the establishment and implementation of the in-service inspection program are the responsibility of 
the operating organization, whose definition is the responsible organization which is authorized by CNEN to operate the nuclear power plants.

According to CNEN NE 1.25, the operating organization shall establish and implement the preservice inspection and in-service inspection programs whose intervals will be defined over the life of the reactor. The pre-service inspection program consists in inspection prior to or during the commissioning of the plant to provide data on initial conditions, supplementing manufacturing and construction data as a basis for comparison with subsequent examinations. This inspection and preoperational test shall be performed in all components subject to inspection in-service, since their results will be used as reference values.

The In-service inspection (ISI) is defined by CNEN as the planned and documented inspection activity over the lifetime of a nuclear power plant from the initial operation. The ISI also involves examinations and tests which are appropriate to the reactor coolant pressure barrier and safety systems in order to check and ensure the maintenance of the structural and functional integrity of structures and components, as established and predicted in the mechanical design of the plant. The inspection intervals for structures, systems and components should be defined in the in-service inspection program. Therefore, before each shutdown period, the operating organization should submit the schedule for the inspection activities which will be carried out at that shutdown plant. After each in-service period, the results should be analyzed and an occasional necessity for updates to the inspection program should be identified.

In the formulation of both inspection programs, pre-service and in-service, as indicated in CNEN 1.25, it is crucial to notice:

a) the list of components to be examined. If any component cannot be inspected as specified in the reference codes, it must not only be analyzed by the operating organization, but also must be submitted for approval by CNEN. In this work, the components are represented by the pressure vessel and its fittings.

b) the maintenance of radiation doses as low as reasonably achievable (ALARA principle) for inspection personnel. In high irradiation areas, the use of remotely operated testing equipment is allowed. 
c) the selection, location and extent of areas to be examined. Figure 8 shows an example of reactor pressure vessel zones inspected.

d) the methodology and techniques used in tests and examinations.

The code ASME Boiler and Pressure Vessel (BPVC), Section XI, presents 3 types of examinations that can be employed in the in-service inspection. The main characteristics of these tests are shown in table 4. The inspection intervals are also recommended by this standard, but it is noteworthy to mention that the frequency of inspections depends on the operator and adopted standards/codes.

Table 4 - Characteristics of Examination Types

\begin{tabular}{|c|c|}
\hline Examination Types & Characteristics $^{1}$ \\
\hline Visual (VT) & $\begin{array}{l}\text { - Detect discontinuities and imperfections on the surface of } \\
\text { components, such as: cracks and corrosion. }\end{array}$ \\
\hline Surface & $\begin{array}{l}\text { - Detect surface discontinuities. } \\
\text { - Techniques applied: magnetic particle, liquid penetrant, } \\
\text { eddy current and ultrasonic method. }\end{array}$ \\
\hline Volumetric & $\begin{array}{l}\text { - Detect discontinuities throughout the volume of material. } \\
\text { - Techniques applied: radiographic, ultrasonic, eddy } \\
\text { current, acoustic emission and ultrasonic method. }\end{array}$ \\
\hline
\end{tabular}

1 This study does not describe the techniques and principles of inspections methodology.

Radiation-induced changes in fracture toughness of RPV materials should be determined from surveillance specimens inside the capsules. These specimens are placed in several positions of the reactor vessel and they are periodically tested. 
Figure 8: Examples of reactor pressure vessel zones inspected

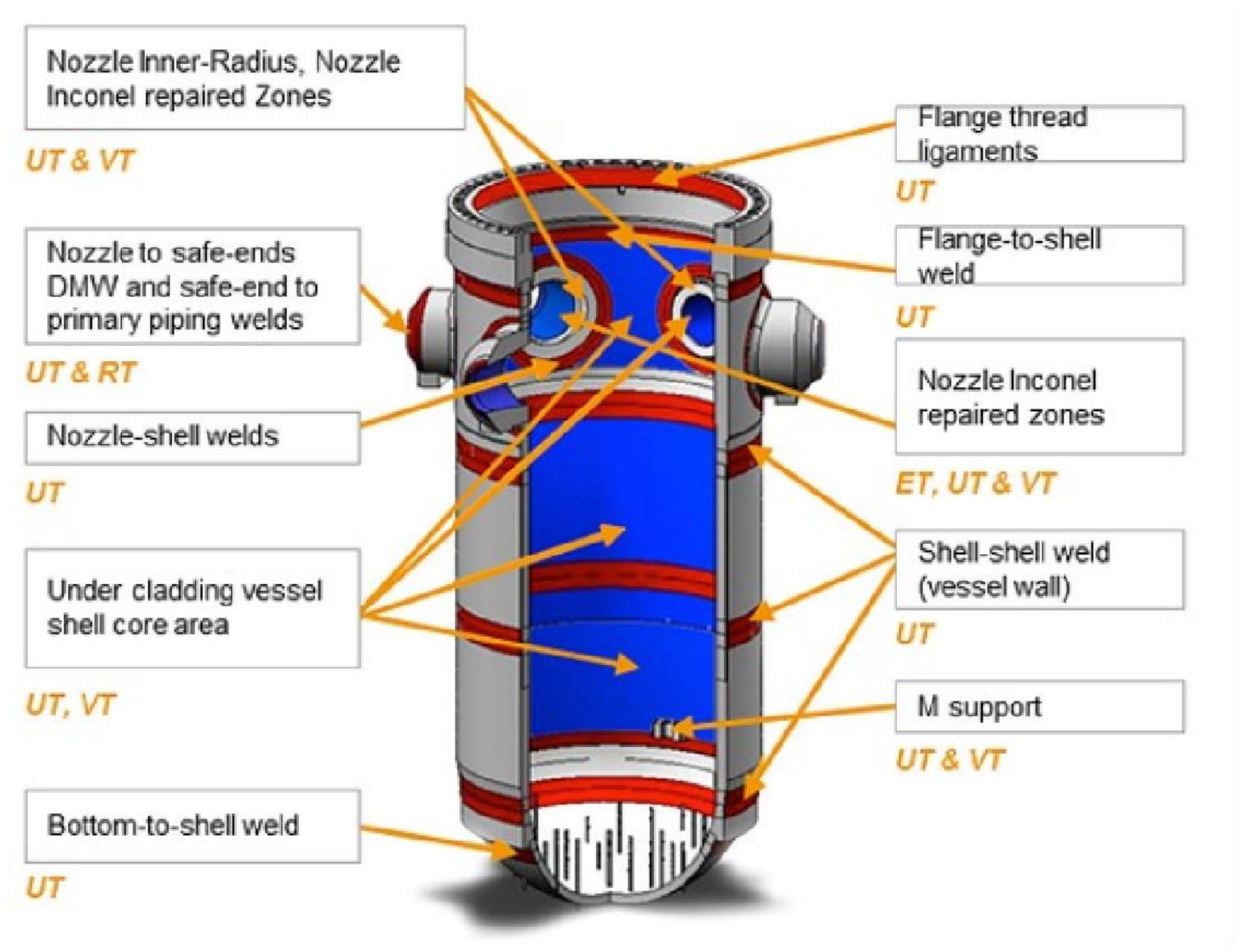

Source: Intercontrole website. [7]

The approval procedures for examinations and tests are required prior to their execution. These procedures should have as minimum content: scope of examination; applicable codes and standards; supporting documents; requirements related to personnel qualifications; methods and equipment to be used; preparation of components to be examined; requirements for calibration and recalibration; execution sequence of examinations; data records; acceptance criteria and checkpoints required.

The methodology and examination techniques should be in accordance with the codes accepted by CNEN. In addition, all equipment together with their accessories used in RPV examinations shall be calibrated according to applicable standards and they shall have the calibration records. The equipment and accessories can also be calibrated before inspections are performed when requested. It is important that the validity of the calibrations be verified regularly. 
Another point is that the inspection personnel during the in-service inspection should be qualified in accordance with the CNEN NE-1.17 - Qualification of Personnel and Certification for Nondestructive Testing on Nuclear Facility Items. For NDT testing methods not provided for in CNEN-NE-1.17, the personnel that performs such tests or examinations should be trained in accordance with a training program established by the operating organization and accepted by CNEN for each specific case.

The operating organization should ensure that the results of any examination are evaluated to determine compliance with the acceptance criteria, according to CNEN NE 1.25 code. Moreover, CNEN should be informed when it is not possible to carry out a specific examination; however, it is necessary to give justifications and to propose alternatives.

The steps for evaluation of the inspection results are not detailed by the CNEN code. In this way, each operating organization can elaborate its own procedure or use recommended methodologies by standards/publications. This topic presents specific points which should be considered. As previously mentioned, inspection results should be evaluated. If discontinuities are detected, it is important to compare the most recent results with previous ones. Consequently, it is possible to identify if there are new anomalies or growth of existing discontinuities. After that, with the characterization of the anomalies, it is possible to verify if detected indications satisfy the acceptance criteria. It is noteworthy to mention for CNEN 1.25 code, if an item is not approved by thresholds of the acceptance standard in procedures of tests or examinations, evaluation and corrective actions should be carried out. However, if there is any new item or a repaired one, it must be subjected to new tests or examinations prior to returning to operation, in order to demonstrate the effectiveness of the corrective actions adopted. 
Therefore, for defects that are not approved by acceptance criteria, it will be necessary to evaluate their cause and carry out a risk assessment. Then, at this stage, it is possible to decide on mitigating actions. Figure 9 shows a flowchart with the steps previously described for evaluating inspection results.

Figure 9: Flowchart for the Evaluation of Inspection Results

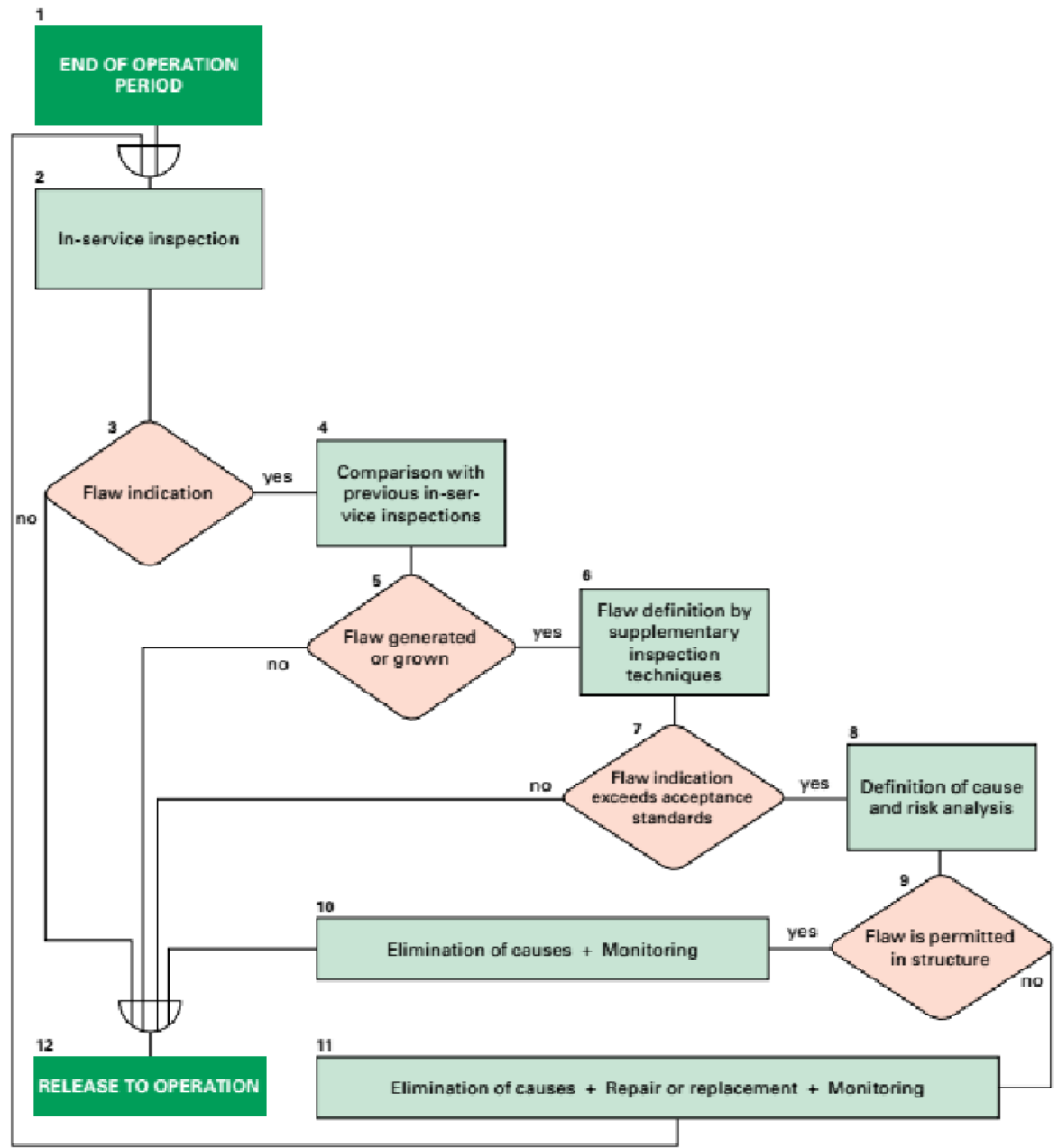

Source: In-Service Inspection of Nuclear Facility Pressure Equipment with NonDestructive Testing Methods, Guide YVL E.5,Stuklex - Finlândia, 2014. [8] 
IT systems are an important tool in the integrity management program of a reactor pressure vessel for evaluating and monitoring inspection results. With the use of computational tools, it is possible to integrate information related to the pressure vessel, such as: design, contract, inspection, maintenance, emergency actions and others. This is one of the requirements of CNEN NE 1.25 that also establishes the data collected from the inspection program should be available and easily accessible. Besides, items whose records have significance to safety should be stored during their useful life.

Figure 10: Data Integration by IT System

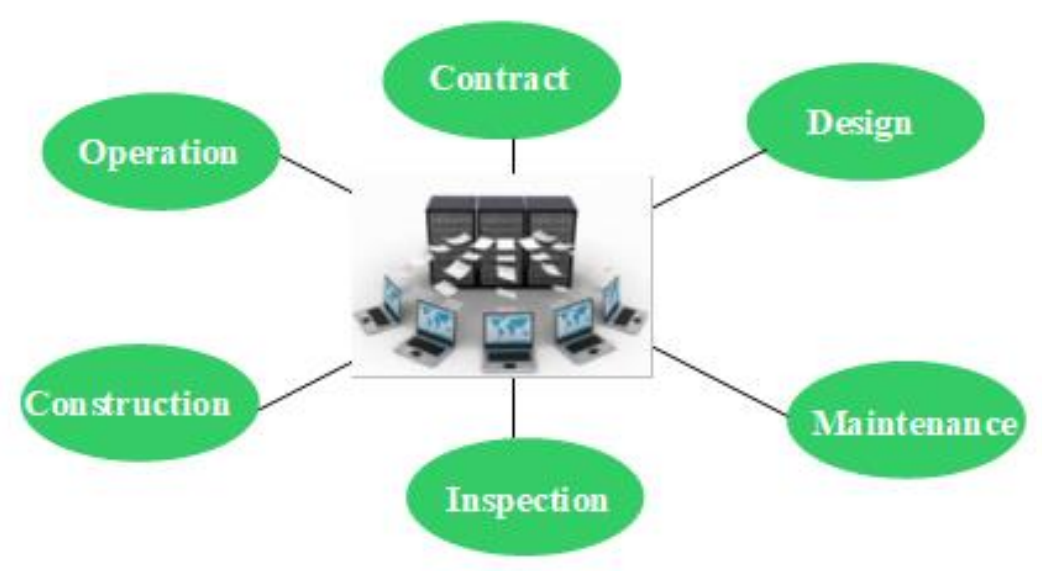

Source: Elaborated by the author

The advantage of using the data integration from IT systems is that it enables:

- Collecting, reviewing and integrating data;

- Accessing design, contract, operational, maintenance, construction and inspection pressure vessel data;

- Monitoring the evolution of detected discontinuities;

- Comparing the inspection results for different techniques;

- Planning and controlling the reports, inspections, contracts and suppliers;

- Managing documents such as procedures, reports, meeting minutes, contracts. 
Data integration is a key element to integrity and risk assessment for reactor pressure vessels. All codes have in common a process that consists in collecting, reviewing and integrating reactor pressure vessel data. This step requires reliable and useful data because the key element of the integrity management program is the integration of all relevant information in the decision-making process. Thus, besides having and knowing the inspection results, it is important to compare and integrate them to perform mitigating actions. Therefore, from data integration, it is possible to identify critical areas in order to ensure the pressure vessel integrity and consequently to contribute with safety improvements to nuclear power plants.

Although commercial IT systems have standard modules, it is recommended that computational applications with custom modules be used because a lot of factors can influence a lifetime of a pressure vessel and each company uses different codes and procedures for the designing, manufacturing and operating of PWR reactors.

\section{CONCLUSIONS}

The purpose of this work was to provide a guide for performing the periodic inspection of PWR reactor pressure vessels considering a set of practices and recommendations already existent. The CNEN NE 1.25 code was employed as reference.

It has been seen that the inspection program scope shall make evident and indicate the acceptance criteria which allows making decisions after inspection results. It was observed that the steps for evaluation of the inspection results are not detailed by the CNEN code, thus the operating organization can elaborate its own procedure or use recommended methodologies by standards/publications.

The main aging mechanisms for PWR reactor pressure vessels were approached in order to guide which properties and failure modes should be monitored. In addition, the effects of irradiation on the main mechanical properties were discussed in this paper. In the periodic inspection program of PWR reactor pressure vessels, it is recommended that the 
methodology and examination techniques be in accordance with the codes accepted by CNEN. The minimum requirements of procedures for examinations and tests also were presented in this study.

Using IT systems as a fundamental tool for the management of pressure vessel integrity, through the integration and comparison of inspection results, allows one to: identify if there are new anomalies or growth of existing discontinuities, identify the cause of discontinuities, decide and plan corrective actions. Furthermore, it is possible to collect design, contract, operational, maintenance and construction pressure vessel data. Thereby, computational systems are useful for complying with one of the requirements of the CNEN code: control data record. Thus, IT applications aim to improve decision-making through data integration and the updating of integrity threats in the PWR reactor pressure vessel.

\section{REFERENCES}

[1] Power Reactor Information System - PRIS - https://pris.iaea.org/pris/. Last accessed: 14 Sept. 2020.

[2]PWR Power Plant Diagram, NRC - https://www.nrc.gov/reading-rm/basicref/students/animated-pwr.html. Last accessed: 14 Sept. 2020.

[3]Curso de Introdução à Engenharia do Núcleo de Reatores, Perrotta, J.A.; Instituto de Pesquisas Energéticas e Nucleares, Apostila - São Paulo, 1999.

[4]Integrity of Reactor Pressure Vessels in Nuclear Power Plants: Assessment of Irradiation Embrittlement Effects in Reactor Pressure Vessel Steels, $\mathrm{n}^{\circ}$ NP-T3.11, International Atomic Energy Agency - IAEA - Vienna, 2009.

[5]Ensaios dos Materiais, Garcia, A., LTC - Rio de Janeiro, $2^{\mathrm{a}}$ ed, 2012.

[6]Fundamentals of Radiation Materials Science: Metals and Alloys, Was, G.S, Springer, 2007.

[7]Exemplos de Áreas Inspecionadas em Vasos de Pressão de PWR, Intercontrole, http://www.intercontrole.com/EN/home-144/www-intercontrole-com-reactorpressurevesselinspection.html. Last accessed: 14 Sept. 2020. 
[8]In-Service Inspection of Nuclear Facility Pressure Equipment with NonDestructive Testing Methods, Guide YVL E.5,Stuklex - Finlândia, 2014.

[9]ASME BPVC, Seção III - Rules for Construction of Nuclear Facility

Components, Divisão I. Boiler and Pressure Vessel Code, American Society of Mechanical Engineers - EUA, 2015.

[10]ASME BPVC, Seção XI - Rules for In-service Inspection of Nuclear Power Plant Components. Boiler and Pressure Vessel Code, American Society of Mechanical Engineers - EUA, 2015.

[11]CNEN NE 1.25. Inspeção em Serviço em Usinas Nucleoelétricas (Resolução CNEN 13/96), CNEN-Brasil, 1996.

[12]Advanced Approach of Reactor Pressure Vessel In-Service Inspection. Pajnić,M., Markulin, K., 10th European Conference on Non-Destructive Testing Russia, 2010.

[13]Reactor Concept Manual, U.S. Nuclear Regulatory Commission Technical Training Center - EUA, 2012.

[14]Degradation Due to Neutron Embrittlement of Nuclear Vessel Steels: A Critical Review about the Current Experimental and Analytical Techniques to Characterise the Material, with Particular Emphasis on Alternative Methodologies, Nuclear Power - Control, Reliability and Human Factors, Ferreño, D., Gorrochategui, I., Gutiérrez-Solan, F., InTech, 2011.

[15]Pressure Vessel Codes: Their Application to Nuclear Reactor Systems, Technical Reports Serie $\mathrm{n}^{\circ} 56$, International Atomic Energy Agency - IAEA Vienna, 1966.

[16]Guide to the Periodic Inspection of Nuclear Reactor Steel Pressure Vessels, Technical Reports Serie $n^{\circ} 99$, International Atomic Energy Agency - IAEA Vienna, 1969. 